\title{
Prophylactic Probiotics for Prevention of Necrotizing Enterocolitis (NEC) in Low Birth Weight Neonates
}

\author{
Anahita Sanaei Dashti ${ }^{1,2}$, Seyyed Abolfazl Afjeh ${ }^{2,3,{ }^{*}, \text { Azita Basiry }}{ }^{3}$, Fariba Shirvani ${ }^{2}$, Kimia \\ Seifi ${ }^{2}$,Zahra Mohammad Taheri ${ }^{4}$ \\ ${ }^{1}$ Professor Alborzi Clinical Microbiology Research Center, Shiraz University of Medical Sciences, Shiraz, IR Iran \\ 2 Pediatric Infections Research Center, Shahid Beheshti University of Medical Sciences, Tehran, IR Iran \\ 3 Mahdieh Medical Center, Shahid Beheshti University of Medical Sciences, Tehran, IR Iran \\ 4 Nikootec Company, Tehran, IR Iran \\ *Corresponding author: Seyyed Abolfazl Afjeh, Newborn Service, Mahdieh Medical Center, Shoosh Square, Shahrezad Street, Tehran, Iran. Tel: +98-2155066282, Fax: +98-2155066282, \\ E-mail:a_afjeh@sbmu.ac.ir.
}

Received: April 16, 2013; Revised: July 06, 2013; Accepted: July 20, 2013

Background: Probiotics are thought to interfere with the mechanisms involving in the pathogenesis of necrotizing enterocolitis in neonates.

Objectives: This study was planned to assess the effect of prophylactic probiotics for the prevention of necrotizing enterocolitis in low birth weight neonates.

Patients and Methods: This prospective triple-blinded, interventional, randomized clinical trial enrolled 136 low birth weight newborn infants with a minimum birth weight of $700 \mathrm{~g}$, from September 2010 to September 2011. The study and control groups were compared regarding; 1 - occurrence of NEC, 2- time to reach full feeding, defined as days required to reach full enteral feeding, 3- duration of hospital course, and 4-incidence of sepsis and death. The study group was fed with milk and Protexin (restore) and the control group was fed with milk and a placebo that was physically indistinguishable from the probiotic powder. SPSS version 16 was used, and P-value less than 0.05 was considered significant.

Results: One hundred thirty six neonates were enrolled in the study. Seventy six (54.4\%) were male. The mean of gestational age and birth weight were 31 weeks and 1407 grams, respectively. The mean age to start feeding was 4.36 days. There was not any significant difference in the NEC cases between the two groups.

Conclusions: This study did not show any benefit from prophylactic probiotics in the prevention of necrotizing enterocolitis in low birth weight neonates which could be probably due to low dose probiotics used.

Keywords: Probiotics; Enterocolitis, Necrotizing; Infant, Low Birth Weight

\section{Background}

Necrotizing enterocolitis (NEC) is one of the most common gastrointestinal emergencies in newborns (1), some reports estimate a $10 \%$ incidence among infants weighing less than $1500 \mathrm{~g}$ with a mortality approaching 30\% (2). Approximately $25 \%$ of survivors experience long-term sequelae (3). It is characterized by bowel wall necrosis of various length and depth. Bowel perforation occurs in one third of the affected infants (4). Although 5-25\% of cases occur in term infants, it is primarily a disease of preterm infants, with most cases occurring in very low birth weight (VLBW) infants (birth weight < $1500 \mathrm{~g}$ ) (5). NEC is categorized into three stages, with clinical symptoms varying from feeding intolerance to severe cardiovascular compromise, coagulopathy, and peritonitis with or without pneumoperitoneum (6).

Approximately $27-63 \%$ of affected infants require surgical intervention (7); strictures, primarily in the colon, occur in more than one third of affected infants (8).

When compared to term infants, VLBW infants at risk of NEC have abnormal fecal colonization, demonstrating a paucity of normal enteric bacterial species, and have delayed onset of bacterial colonization $(9,10)$.

NEC is a multifactorial disease which results from an interaction between the loss of mucosal integrity (due to ischemia, inflammation and infection) and the host response to that injury (in the form of circulatory, in flammatory and immune-mediated response). The most common risk factors cited are prematurity (low birth weight), enteral feeding, and colonization by bacteria

Implication for health policy/practice/research/medical education:

NEC is one of the major problems of VLBW Infants admitted to the NICU with high morbidity and mortality, several risk factors are mentioned in literature and different methods are proposed for prevention of it, the last opinion is on probiotic therapy of preterm infants, several studies shows its benefits for reduction of NEC and associated morbidity and mortality. This research is the first study of prophylactic probiotic in preterm neonates in NICU of the Mahdieh hospital to evaluate its effect for neonates of our country.

Copyright (C) 2014, Pediartric Infections Research Center. This is an Open Access article distributed under the terms of the Creative Commons Attribution License (http://creativecommons.org/licenses/by/3.0), which permits unrestricted use, distribution, and reproduction in any medium, provided the original work is properly cited. 
such as Escherichia coli, Klebsiella, Clostridium perfringens, Staphylococcal epidermidis, and Rotavirus $(11,12)$.

Unlike healthy infants, preterm infants develop a different bowel colonization pattern which may contribute to the development of NEC and other infections. As a result, it is hypothesized that the proactive colonization of preterm infants using probiotic supplements may help to reduce the overgrowth of pathogens in the bowels of preterm infants and decrease the likelihood of infections including NEC and feeding tolerance in them.

Probiotics are defined at 2001 by the world health organization as "live microorganisms, which when administered in adequate amount confer a health benefit on the host". The American academy of pediatrics has not issued recommendations for the routine use of probiotics up to now; however, it does support their use on an individual basis in patients who may benefit from therapy (13).

Recently several preventive strategies are presented including: antenatal steroid, human milk feeding, enhancement of platelet-activating factor, use of platelet-activating factor receptor antagonists, and probiotics (14).

\section{Objectives}

The main aim of this study was to assess the effect of probiotics in prevention of NEC in low birth weight neonates.

\section{Patients and Methods}

The study was a prospective triple-blinded, interventional, randomized clinical trial which enrolled 136 low birth weight newborn infants with a minimum birth weight of 700 grams, from September 2010 till 2011. It was performed in neonatal intensive care unit (NICU) of Mahdieh hospital which is an academic center. After planning the research and before putting it into practice, all the ward staff were informed and instructed about implementation of the study.

Parental written informed consents were taken from parents before enrolling a neonate in the study. Once vital signs were stable, active bowel sounds were present, no abdominal distension was present, and no blood or bile in gastric aspirates was detected, feeding was started. Neonates were randomized into two groups to receive standard milk supplemented with once a day probiotics supplement, starting from the first feed, or a placebo, until discharge or death. Inclusion criteria were: birth weight of 700-1800 g, stable hemodynamic, be able to have enteral feeding, and written parental consent, exclusion criteria were: evidence or suspicion of congenital intestinal obstruction or perforation, prenatal or postnatal diagnosis of gastroschisis, large omphalocele, or congenital diaphragmatic hernia, and major congenital anomalies.

Primary outcome measures compared between the study and control groups were: 1) occurrence of NEC, 2) time to reach full feeding, defined as days required to reach full enteral feeding $(100 \mathrm{ml} / \mathrm{K} / \mathrm{d}), 3)$ duration of hospital course, 4) sepsis or death. NEC was assessed and scored according to the Bell's staging (6). Sepsis was defined as having clinical signs in favor of sepsis, plus positive results for blood culture.

The study group was fed with milk and Protexin (Restore): $1 \times 109$ CFU (colony forming unit), one gram (one sachet) contains: Lactobacillus acidophilus, Lactobacillus rhamnosus, Bifidobacterium longum, Lactobacillus bulgaricus, Lactobacillus casei, Streptococcus thermophilus, Bifidobacterium breve, and Bifidobacterium, probiotics international limited., The United Kingdom. Neonates weighing less than $1000 \mathrm{~g}$ were fed with a half of sachet once daily $(5 \times 108$ CFU of probiotics), neonates weighing 1001-1500 g were fed with $3 / 4$ of a sachet once daily $(7.5 \times 108 \mathrm{CFU}$ of probiotics), neonates weighing more than $1500 \mathrm{~g}$ were fed with a full sachet once daily $(1 \times 109$ CFU of probiotics). The control group was fed with milk and a placebo that was physically indistinguishable from the probiotic powder.

Restore and placebo sachets were stored in a refrigerator at a temperature between $4^{\circ} \mathrm{C}$ and $8^{\circ} \mathrm{C}$ and mixed with milk before feeding by trained personnel. To blind the trial the probiotic and placebo sachets were set in similar indistinguishable packages. For further blinding, the sachets were labeled with numbers that was unique for a patient.

After starting the feeding, infants were observed continuously by a chart containing basic information like daily weight, feeding volume, abdominal girth, appearance of erythema of abdominal wall, loose stools with blood, vomiting, and orogastric tube suction volume. The amount of feeding was advanced slowly, if tolerated, with no more than a $20 \mathrm{~mL} / \mathrm{kg} / \mathrm{d}$.

Feeding was discontinued if there was any sign of feeding intolerance (defined as the presence of gastric aspirate in the amount that was more than a half of the previous feeding or abdominal distension). Infants received total parenteral nutrition until a half of the calories were supplied by the oral route. With any suspicion to NEC the attending neonatologist was informed to visit and assess the neonate. Gestational age was assessed from history of the last menstrual period, by sonography and after birth by the new Ballard scores.

Demographic and clinical data and potential risk factors that might have an effect on the incidence of NEC were recorded from the medical records (Table 1).

\subsection{Statistics}

SPSS 16 was used. The 2_test was used to analyze the categorical data, along with Fisher's exact test when applicable. The Student's t test was used for continuous data. A logistic regression model was used to analyze the treatment effects on the primary and secondary outcome vari- 
ables (death, NEC, and sepsis).

\begin{tabular}{|c|c|c|}
\hline Variables & Group A $(n=69)$ & Group B $(n=67)$ \\
\hline \multicolumn{3}{|l|}{ Sex, No. (\%) } \\
\hline Male & $32(46.38)$ & $42(62.69)$ \\
\hline Female & $37(53.62)$ & $25(37.31)$ \\
\hline \multicolumn{3}{|l|}{ Delivery, No. (\%) } \\
\hline $\mathrm{C} / \mathrm{S}^{\mathrm{a}}$ & $52(75.36)$ & $60(89.55)$ \\
\hline $\mathrm{NVD}^{\mathrm{a}}$ & $17(24.64)$ & $7(10.45)$ \\
\hline Gestational age $(w),($ mean $\pm S D)$ & $31.12 \pm 2.68$ & $31.37 \pm 2.6$ \\
\hline Birth weight $(g),($ mean \pm SD $)$ & $1372.83 \pm 279.03$ & $1440.90 \pm 252.68$ \\
\hline \multicolumn{3}{|l|}{ Birth weight, (g), No. (\%) } \\
\hline$\leq 1000$ & $11(15.94)$ & $5(7.46)$ \\
\hline $1000-1500$ & $33(47.83)$ & $29(43.28)$ \\
\hline $1501-1800$ & $25(36.23)$ & $33(49.25)$ \\
\hline \multicolumn{3}{|l|}{ Apgar, (mean \pm SD) } \\
\hline $1 \mathrm{~min}$ & $7.84 \pm 1.56$ & $7.79 \pm 1.21$ \\
\hline $5 \mathrm{~min}$ & $9.25 \pm 1.06$ & $9.2 \pm 0.9$ \\
\hline \multicolumn{3}{|l|}{ CPR, No. $(\%)^{\mathrm{a}}$} \\
\hline \multicolumn{3}{|l|}{ Initial steps } \\
\hline yes & $25(36.23)$ & $26(38.81)$ \\
\hline no & $44(63.77)$ & $41(61.19)$ \\
\hline \multicolumn{3}{|l|}{ Advance } \\
\hline yes & $15(21.74)$ & $14(20.9 \%)$ \\
\hline no & $54(78.26)$ & $53(79.1 \%)$ \\
\hline \multicolumn{3}{|l|}{ Surfactant, No. (\%) } \\
\hline yes & $34(49.28)$ & $33(49.25)$ \\
\hline no & $35(50.72)$ & $34(50.75)$ \\
\hline \multicolumn{3}{|l|}{ Mechanical Ventilation, No. (\%) } \\
\hline yes & $38(55.07)$ & $30(44.78)$ \\
\hline no & $31(44.93)$ & $37(55.22)$ \\
\hline \multicolumn{3}{|l|}{ Dopamine, No. (\%) } \\
\hline yes & $8(11.59)$ & $4(5.97)$ \\
\hline no & $61(88.41)$ & $63(94.03)$ \\
\hline \multicolumn{3}{|l|}{ Preeclampsia, No. (\%) } \\
\hline yes & $19(27.54)$ & $8(11.94)$ \\
\hline no & $50(72.46)$ & $59(88.06)$ \\
\hline \multicolumn{3}{|l|}{ Chorioamnionitis, No.(\%) } \\
\hline yes & $1(1.45)$ & $0(0)$ \\
\hline no & $68(98.55)$ & $66(100)$ \\
\hline \multicolumn{3}{|l|}{ PROM $^{\mathrm{a}}$, No. (\%) } \\
\hline yes & $10(14.49)$ & $5(7.46)$ \\
\hline no & $59(85.51)$ & $62(92.54)$ \\
\hline $\mathrm{NPO}^{\mathrm{a}}$ duration $(\mathrm{d}),($ mean $\pm \mathrm{SD})$ & $3.57 \pm 3.39$ & $3.38 \pm 3.13$ \\
\hline Age of starting enteric feeding, (mean \pm SD) & $4.54 \pm 3.44$ & $4.22 \pm 2.95$ \\
\hline
\end{tabular}


Type of feeding, No. (\%)

\begin{tabular}{|c|c|c|}
\hline breast milk & $29(42.65)$ & $18(27.27)$ \\
\hline formula milk & $4(5.88)$ & $4(6.06)$ \\
\hline both & $35(51.47)$ & $44(66.67)$ \\
\hline \multicolumn{3}{|l|}{ UTI $^{\mathrm{a}}$, No. (\%) } \\
\hline yes & $1(1.45)$ & $0(0)$ \\
\hline no & $68(98.55)$ & $67(100)$ \\
\hline \multicolumn{3}{|l|}{ IVH $^{\mathrm{a}}$, No. (\%) } \\
\hline no & $46(66.67)$ & $49(73.13)$ \\
\hline Grade I & $9(13.04)$ & $9(13.43)$ \\
\hline Grade II & $9(13.04)$ & $4(5.97)$ \\
\hline Grade III & $5(7.25)$ & $3(4.48)$ \\
\hline Grade IV & $0(0)$ & $2(2.99)$ \\
\hline \multicolumn{3}{|l|}{ PDA $^{\mathrm{a}}$, No. (\%) } \\
\hline yes & $39(56.52)$ & $44(65.67)$ \\
\hline no & $30(43.48)$ & $23(34.33)$ \\
\hline \multicolumn{3}{|l|}{ Brufen, No. (\%) } \\
\hline yes & $7(20)$ & $8(20)$ \\
\hline no & $28(80)$ & $32(80)$ \\
\hline \multicolumn{3}{|c|}{ Umbilical artery catheter (UAC), No. (\%) } \\
\hline yes & $0(0)$ & $0(0)$ \\
\hline no & $69(100)$ & $67(100)$ \\
\hline
\end{tabular}

a Abbreviations: CPR,cardio pulmonary resuscitation; CS, cesarean section; IVH, intra ventricular hemorrhage; PDA, patent ductus arteriosus; PROM, premature rupture of memberane; NPO, nothing per Os; NVD, normal vaginal delivery; UTI, urinary tract infection

Statistical analysis used unpaired student t-test for continuous variables and chi-square test for categorical variables. Values were expressed for the mean and standard deviation. P-value less than 0.05 was considered significant.

\section{Results}

One hundred thirty six neonates were enrolled in the study. 74 (54.4\%) were male. The mean of gestational age and birth weight were 31 weeks and 1407 grams, respectively (Table 1).

The mean age to start feeding was 4.36 days. There was not any significant difference in the NEC, feeding tolerance, time to reach full feeding, sepsis and death between the two groups (Table 2).

\section{Discussion}

Intestinal flora is supposed to have a considerable role in the pathogenesis of NEC. The beneficial effect of probiotics as "good microbes" on the prevention of NEC in premature and low birth weight neonates are shown by a couple of studies, but according to our research, there was no difference between the study and the control groups regarding the incidence of NEC.

A prospective, masked, randomized control trial was performed by Hung-Chih Lin (14) to evaluate the effects of probiotics in reducing the incidence and severity of NEC in VLBW infants. The infants in the study group were fed with Lactobacillus acidophilus and Bifidobacterium infantis twice daily until discharge. Three hundred sixty-seven infants were enrolled: 180 in the study group and 187 in the control group. The incidence of NEC (> stage II) was significantly lower in the study when compared to the control group (2 of 180 vs. 10 of 187), other risk factors such as NVD, mechanical ventilation, postnatal steroid, Apgar at 5 min, were not significant.

In a double-blinded study accomplished in 12 Italian NICUs (15), five hundred eighty-five newborns with a gestational age $<33$ weeks or birth weight $<1500 \mathrm{~g}$ were randomized to receive standard milk feed supplemented with Lactobacillus GG (Dicoflor), (Dicofarm, Rome, Italy) in a dose of $6 \times 109$ CFU once a day until discharge. Although UTIs (3.4\% vs. 5.8\%) and NEC (1.4\% vs. $2.7 \%$ ) were found less frequently in the probiotic group compared to the control group, but these differences were not significant. Bacterial sepsis was more frequent in the probiotics group $(4.4 \%, \mathrm{n}=11)$ than the placebo group $(3.8 \%, n=9)$, but the difference was not significant. There was also no difference between the two groups regarding sepsis, feeding tolerance or hospital course. 
Sanaei A et al.

\begin{tabular}{|c|c|c|c|}
\hline Outcomes & $\operatorname{Group} A(n=69)$ & Group B $(n=67)$ & P-Value \\
\hline Time to full fed $(\mathrm{d}),($ mean \pm SD $)$ & $13.83 \pm 10.99$ & $16.11 \pm 14.82$ & 0.33 \\
\hline Age at full fed $(d),($ mean \pm SD $)$ & $18.30 \pm 12.98$ & $20.35 \pm 15.78$ & 0.43 \\
\hline NEC, No. (\%) & & & 1.00 \\
\hline no & $59(85.51)$ & $59(88.06)$ & \\
\hline Stage I & $8(11.59)$ & $7(10.45)$ & \\
\hline Stage II & $1(1.45)$ & $1(1.49)$ & \\
\hline Stage III & $1(1.45)$ & $0(0)$ & \\
\hline Sepsis (clinical), No. (\%) & & & 0.51 \\
\hline yes & $45(65.22)$ & $40(59.7)$ & \\
\hline no & $24(34.78)$ & $27(40.3)$ & \\
\hline Hospital course $(d),($ mean $\pm S D)$ & $27.2 \pm 18.44$ & $28.81 \pm 19.51$ & 0.62 \\
\hline Duration of antibiotics $(d),($ mean \pm SD) & $21.12 \pm 15$ & $23.88 \pm 18.58$ & 0.34 \\
\hline Death, No. (\%) & & & 0.25 \\
\hline yes & $8(11.59)$ & $4(5.97)$ & \\
\hline no & $61(88.41)$ & $63(94.03)$ & \\
\hline
\end{tabular}

In a bicentric, double-blind, randomized controlled clinical trial performed by Carole Rouge (16) which was stratified for center and birth weight, 45 infants received enteral probiotics (Bifidobacterium longum BB536 and Lactobacillus rhamnosus GG; BB536-LGG), and 49 received placebo.

The primary endpoint was the percentage of infants receiving $50 \%$ of their nutritional needs via enteral feeding on the 14th day of life for the evaluation of feeding tolerance by probiotics. The primary endpoint was not significantly different between the probiotic (57.8\%) and placebo (57.1\%) groups ( $\mathrm{P} 1 / 40.95)$.

A double-blind, placebo controlled, randomized clinical study was performed (17) on 69 preterm infants to investigate the role of Bifidobacterium lactis Bb12 supplementation in modifying the gut microbiota. Bifidobacterial numbers were significantly higher in the probiotic than placebo. The infants supplemented with Bb12 also had lower viable counts of Enterobacteriaceae and Clostridium spp. than the infants in the placebo group. Supplementation of B. lactis Bb12 did not reduce the colonization by antibiotic-resistant organisms in the study population.

In our study some factors could be responsible for the state of "no difference" such as: species of probiotics, the control group and small number of NEC in our neonates during the study period. There were only two cases of stage II NEC and one case of stage III NEC (2.2\%) in our neonates which is fortunate for our NICU but we expected that at least other major problems such as feeding intolerance, age to reach to full feeding and late onset sepsis improves, but these data also had no difference between the study and control groups.

Other factor that might have an impact on the result of our study was the dose of supplied probiotics, although according to the literature probiotics were used in doses up to $25 \times 109 \mathrm{CFU}(12,15,18-20)$, but we used its low dose, because this was the first study in our country and especially in ELBW infants, but in future study we hope to use higher doses of probiotics.

Another factor that may have an interaction with the colonization and function of the probiotics or even the incidence of NEC is concurrent antibiotic usage. Antibiotics (initially Ampicillin plus Gentamicin and changing according to the clinical and paraclinical findings) were used in almost all of the neonates that were enrolled in the study. This extensive use of antibiotics may lessen the function of probiotics by impeding their viability and/or colonization. Moreover, antibiotics may reduce the incidence of NEC in both groups, impeding to detect a difference between the groups.

In conclusion, although our study did not support benefit of probiotics for prevention of NEC and reduction of other problems, but we must notice the Cochrane review at 2011 which showed in 16 randomized trials with 2842 infants, that enteral probiotics reduced the incidence of sever NEC, morbidity and NEC related mortality (18), also Deshpande meta-analysis (21) of 11 RCT with 2176 VLBW infants (<34 w. gestation) showed that probiotics supplement had significant benefit to reduce NEC and death, so they recommend no need for additional study anymore and give probiotics if it is available!.

\section{Acknowledgements}

This study was supported by the Pediatric Infections Research Center, we are grateful about supplying the probiotics and placebos from the Protexin Health Care Com- 
pany, and their agency in Iran, Nikootec Company, also we wish to thank all physicians and nurses in the NICU of Mahdieh Medical Center, and also Dr. Ahmad Reza Shamshiri for analysis of this manuscript.

\section{Authors' Contribution}

None Declared.

\section{Financial Disclosure}

There is no conflict of interest.

\section{Funding/Support}

There is no support.

\section{References}

1. Caplan MS, Miller-Catchpole R, Kaup S, Russell T, Lickerman M, Amer M, et al. Bifidobacterial supplementation reduces the incidence of necrotizing enterocolitis in a neonatal rat model. Gastroenterology. 1999;117(3):577-83.

2. Zhang L, Li N, Neu J. Probiotics for preterm infants. Neo Rev. 2005;6:e227-32.

3. Hintz SR, Kendrick DE, Stoll BJ, Vohr BR, Fanaroff AA, Donovan EF, et al. Neurodevelopmental and growth outcomes of extremely low birth weight infants after necrotizing enterocolitis. Pediatrics. 2005;115(3):696-703.

4. Kafetzis DA, Skevaki C, Costalos C. Neonatal necrotizing enterocolitis: an overview. Curr Opin Infect Dis. 2003;16(4):349-55.

5. Kosloske AM. Epidemiology of necrotizing enterocolitis. Acto Paediatr Suppl.1994;396:2-7.

6. Bell MJ, Ternberg JL, Feigin RD, Keating JP, Marshall R, Barton L et al. Neonatal necrotizing enterocolitis. Therapeutic decisions based upon clinical staging. Ann Surg. 1978;187(1):1-7.

7. Lee JS, Polin RA. Treatment and prevention of necrotizing enterocolitis. Semin Neonatol. 2003;8(6):449-59.

8. Ricketts RR. Surgical treatment of necrotizing enterocolitis and the short bowel syndrome. Clin Perinatol.1994;21(2):365-87.

9. Goldmann DA, Leclair J, Macone A. Bacterial colonization of neonates admitted to an intensive care environment. J Pediatr
1978;93(2):288-93.

10. Gewolb IH, Schwalbe RS, Taciak VL, Harrison TS, Panigrahi P. Stoo microflora in extremely low birthweight infants. Arch Dis Child Fetal Neonatal Ed.1999;80(3):F167-73.

11. Samanta M, Sarkar M, Ghosh P, Ghosh Jk, Sinha Mk, Chatterjee S. Prophylactic probiotics for prevention of necrotizing enterocolitis in very low birth weight newborns. $J$ Trop Pediatr. 2009;55(2):128-31.

12. Piazza AJ, Stoll BJ. Digestive disorder in the fetus and neonatal infants. In: Kliegman RM, Behrman RE, Jenson HB, Stanton BF, editors.The Fetus and the Neonatal Infant in Nelson Textbook of Pediatrics.18th Ed, Vol.1, Philadelphia: Saunders, Elsevier; 2007.

13. Thomas DW, Greer FR. Probiotics and prebiotics in pediatrics. Pediatrics. 2010;126(6):1217-31.

14. Lin HC, Su BH, Chen AC, Lin TW, Tsai CH, Yeh TF, et al. Oral probiotics reduce the incidence and severity of necrotizing enterocolitis in very low birth weight infants. Pediatrics. 2005;115(1):1-4.

15. Dani C, Biadaioli R, Bertini G, Martelli E, Rubaltelli FF. Probiotics feeding in prevention of urinary tract infection, bacterial sepsis and necrotizing enterocolitis in preterm infants. A prospective double-blind study. Biol Neonate. 2002;82(2):103-8.

16. Rouge C, Piloquet H, Butel MJ, Berger B, Rochat F, Ferraris L, et al Oral supplementation with probiotics in very-low-birth-weight preterm infants: a randomized, double-blind, placebo-controlled trial. Am JClin Nutr. 2009;89(6):1828-35.

17. Mohan R, Koebnick C, Schildt J, Mueller M, Radke M, Blaut M. Effects of Bifidobacterium lactis Bb12 supplementation on body weight, fecal $\mathrm{pH}$, acetate, lactate, calprotectin, and IgA in preterm infants. Pediatr Res. 2008;64(4):418-22.

18. Alfaleh K, Anabrees J, Bassler D, Al-Kharfi T. Probiotics for prevention of necrotizing enterocolitis in preterm infants. Cochrane Database Syst Rev. 2011;(3):CD005496.

19. Lin HC, Hsu CH, Chen HL, Chung MY, Hsu JF, Lien RI, et al. Oral probiotics prevent necrotizing enterocolitis in very low birth weight preterm infants: a multicenter, randomized, controlled trial. Pediatrics. 2008;122(4):693-700

20. Manzoni P, Mostert M, Leonessa ML, Priolo C, Farina D, Monetti C, et al. Oral supplementation with Lactobacillus casei subspecies rhamnosus prevents enteric colonization by Candida species in preterm neonates: a randomized study. Clin Infect Dis. 2006;42(12):1735-42

21. Deshpande G, Rao S, Patole S, Bulsara M. Updated meta-analysis of probiotics for preventing necrotizing enterocolitis in preterm neonates. Pediatrics. 2010;125(5):921-30. 